\title{
Behaviour of Listeria Monocytogenes in Pasteurization Milk during Refrigerator Storage
}

\author{
Ratmawati Malaka ${ }^{1}$, Syahriana Sabil ${ }^{2}$, Kusumandari Indah Prahesti ${ }^{1}$ and \\ Farida Nur Yuliati ${ }^{1}$
}

\begin{abstract}
Milk is an excellent medium for the growth of microorganisms including Listeria monocytogenes. Some pathogenic bacteria can survive after pasteurization in milk, and these bacteria can contaminate again after storage. The purpose of this study was to determine the behavior of $L$. monocyogenes after pasteurization in refrigerator storage. Fresh milk is pasteurized at $75,80,85,90$ and $95^{\circ} \mathrm{C}$ for 1 minute and stored at refrigerator temperature for 1 day, 1 week and 2 weeks. Characteristics of growth and total number of L. monocytogenes in Listeria Selective agar Base medium were observed. The results showed that the total number of $L$. monocytogenes at the control temperature before pasteurization was $7.91(\log \mathrm{cfu} / \mathrm{ml})$. At pasteurization temperatures of 75,80 and $85^{\circ} \mathrm{C}$ for $1 \mathrm{~min}$, the number of $L$. monocytogenes bacteria were decrease to $5.83,3.82$ and $1.18(\log \mathrm{cfu} / \mathrm{ml}$ ), respectively, whereas the total numbers of this bacteria on pasteurization temperatures of 90 and 95 $\mathrm{C}$ were all listeria killed, but can grow back in refrigerator storage $\left(4^{\circ} \mathrm{C}\right)$.
\end{abstract}

Keywords: Pasteurization, milk, Listeria monocytogenes, refrigerator storage

\section{Introduction}

Listeria monocytogenes has been found in raw foods of animal origin. Listeria monocytogenes is a Gram-positive, rod-shaped, facultative anaerobic bacterium that has been linked to food-borne illness outbreaks with an unusually high mortality rate of $20 \%$ (McLauchlin et al., 2004). Milk is a good medium for microbial growth. Cheeses are considered at risk foodstuffs (Marth and Ryser, 1990; Greenwood et al., 1991). Listeria monocytogenes is a bacterial pathogen causing outbreaks in food (food-borne bacteria) resulting in the disease listeriosis in humans and animals (Menendez et al., 1997; (Rosenow and Marth, 1987; Kasalica et al., 2011). Listeriosis causes abortions in pregnant females, neonatal sepsis, and severe infections such as septicemia and meningoencephalitis in susceptible hosts (Farber and Peterkin, 1991; Paillardet al., 2003). Harsoyo and Andini (2002) stated that L. monocytogenes is the cause of serious disease with a mortality rate of $20-30 \%$. Listeria monocytogenes is widely distributed in the environment, can be found in the soil, animal feces, water and plant decay. Cattle infected with $L$. monocytogenes do not generally show symptoms but can contaminate the surrounding environment, and raw foods such as meat, dairy and other animal products. The prevalence of $L$. monocytogenes in selected samples of milk and milk product is $2.6 \%$ on average (raw bulk milk is $2.1 \%$; raw milk from tanker trailer is $5.1 \%$; raw milk from silo prior to pasteurization is $15 \%$; raw milk from the balance tank of the pasteurizer is $14 \%$; pasteurized milk is 5\%; semi-finished and final product is $0 \%$ ) (Navratilova et al., 2004).Silva et al. (2003) studied the occurrence of Listeria spp. in critical control points and the environment of the Minas Frescal cheese processing plant. This study found that 
from the total of 218 samples, thirteen were positive for Listeria; of these, 2 samples were L. monocytogenes.

Pasteurization is a process designed to destroy pathogenic microorganisms in raw milk (Kameni et al., 2002; Elrahmanet al., 2013; Sarkar, 2015). The growth of L. monocytogenes in HTST pasteurized fresh milk is a critical point for human health. Handling of milk after milking can cause dangerous diseases (zoonoses). Precautions against the dangers of milk consumption can be dealt with by heating. Pasteurization is a heating process that uses temperatures below $100^{\circ} \mathrm{C}$, aiming to deactivate enzymes and extend the shelf-life. Fresh milk is pasteurized by HTST which is expected to kill microorganisms and all unwanted pathogens, including L. monocytogenes. The results of the study of Nadal et al. (2007) stated that $L$. monocytogenes is able to survive at a temperature of $72^{\circ} \mathrm{C}$ for 15 seconds. The storage of pasteurized milk in a refrigerator (at $4^{\circ} \mathrm{C}$ ) is expected to extend the shelf-life.

Studies done to evaluate the thermal resistance of $L$. monocytogenes have produced conflicting results (Bearns and Girards, 1958; Beery et al., 1985; Bradshaw et al., 1985). Listeria monocytogenes is an intracellular parasite and may be present within leucocytes in contaminated milk. Some investigators suggest that an intracellular state may confer heat resistance to the organism and allow some listeriae within leukocytes to survive pasteurization. According to the report by Doyle et al. (1987), although L. monocytogenes was isolated from milk heated at $72.2^{\circ} \mathrm{C}$ for $16.4 \mathrm{~s}$, the organism was not detected in the few trials of milk heated at $76.4^{\circ} \mathrm{C}$ for $15.4 \mathrm{~s}$. The purpose of this study was to determine the effect of High Temperature Short Time (HTST) pasteurization on the survival of $L$. monocytogenes and its ability to grow in storage at refrigerator temperature.

\section{Materials and Methods}

\subsection{Sampling and Pasteurization of Raw Milk}

Raw milk samples were obtained from a dairy farm in Enrekang (about 5 hours driving distance from the laboratory), South Sulawesi, Indonesia; samples were transported using a cool box to the Biotechnology Milk Processing Technology Laboratory. All samples were placed in a sterile whirlpak bag, kept at $5^{\circ} \mathrm{C}$, and processed within $24 \mathrm{~h}$ of collection. Research was conducted at the Laboratory of Microbiology, Faculty of Animal Husbandry Hasanuddin University in Makassar, Indonesia.

Fresh milk to be pasteurized was put into test tubes, with $10 \mathrm{ml}$ per tube. HTST pasteurized fresh milk was heated at 5 different temperatures (temperature $75^{\circ} \mathrm{C}, 80^{\circ} \mathrm{C}$, $85^{\circ} \mathrm{C}, 90^{\circ} \mathrm{C}$ and $95^{\circ} \mathrm{C}$ ) at a time of 1 minute each, and 1 tube of fresh milk was used as a control (without pasteurization). Furthermore, the milk that had been pasteurized was then stored in the refrigerator at $4^{\circ} \mathrm{C}$ for 1 day, 1 week and 2 weeks.

\subsection{Isolation and Identification of Listeria monocytogenes}

This research used biochemical methods for listeria identification using selective media for listeria (Listeria Selektive Agar) and then a confirmation test with a biochemical characteristics test such as the sugar fermentation test, the citrate reduction or the CAMP (Christie, Atkins, Munch-Petersen) test. Milk sampling was performed by plating serial (1:10) dilution onto Listeria Selective Agar (LSA) and incubating the agar plates at $35^{\circ} \mathrm{C}$. Samples of $1 \mathrm{ml}$ of the dilution were incorporated into a sterile petri dish 
and then Listeria Selective Agar was added for storage at $45-50^{\circ} \mathrm{C}$ for about $15 \mathrm{ml}$. Listeria was selectively incubated after being solidified and incubated in an incubator at a temperature of $35^{\circ} \mathrm{C}$ for 24 hours.

\subsection{Morphological observation}

Colonies of bacteria in a petri dish were observed for color, nature, edge, elevation, surface, and size and color changes of media bacteria.

\subsection{Gram staining}

Bacteria to be colored were taken and a fixed loop was formed over the object glass; this was dripping with crystal violet and was subsequently allowed to stand for 1-2 minutes before being washed with distilled water. Then, Lugol was used and the solution was allowed to stand for 1-2 minutes before being washed with $95 \%$ alcohol to clean the sample, followed by distilled water. The mixture was given safranin and allowed to stand for 1-2 minutes before being washed with distilled water and then dried. Preparations were examined under a microscope to assess the structure, morphology and color of the cells of the bacteria.

\section{Result and Discussions}

\subsection{Morphological characteristics}

Based on the results of the study of morphological characteristics and Listeria monosytogenes colonies adapted to Bergey's Manual of Systematic Bacteriology (1994) can be seen in Table 1 and Figure 1. Members of the Listeria genus are short rods, facultative anaerobic, Gram positive, not forming spores and capsules, distributed individually and in form of short chains. L. monocytogenes creates during exponential phase a toxin called listerilysin $\mathrm{O}$ (hemolysin), which leads to in-vitro hemolysis on blood agar (Kasalica et al., 2011).
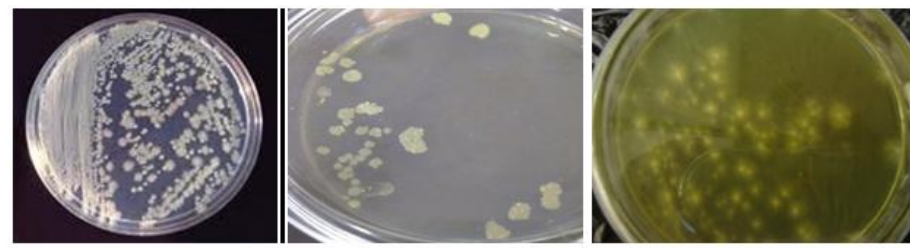

Figure 1. Colonies of Listeria monocytogenes on Listeria Selective Agar (LSA)

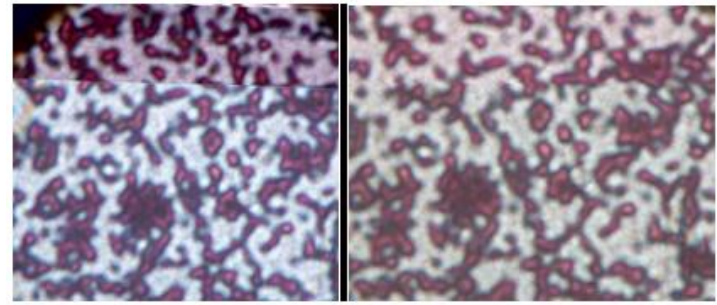

Figure 2. Listeria monocytogenes morphology with Gram staining 
Identification of isolates obtained on LSA was evaluated by observation of colonial morphology, cellular morphology and hemolytic reaction in sheep blood $(5 \% \mathrm{v} / \mathrm{v})$ agar and then compared with the characteristics of Listeria monocytogenes described in Bergeys manual (Figure 1 and 2). Figure 1. shows that the colony of Listeria monocytogenes was colony color from white to yellowish and opaque, a serrated edge indicating that this bacterium form longer rods with long filaments. Figure 2 shows that the isolate bacteria of HTST pasteurized milk made through Gram staining are Gram positive, do not form spores and capsules, are individually distributed and form short chains, some of which form $\mathrm{V}$ and $\mathrm{Y}$, indicated the isolates are Listeria monocytogenes. In the motility test using indole media showed that this isolate is mobile when incubated at $25^{\circ} \mathrm{C}$, this is because these bacteria form the peritrichous flagella (Kasalica et al., 2011), this also causes the colony to form a filament.

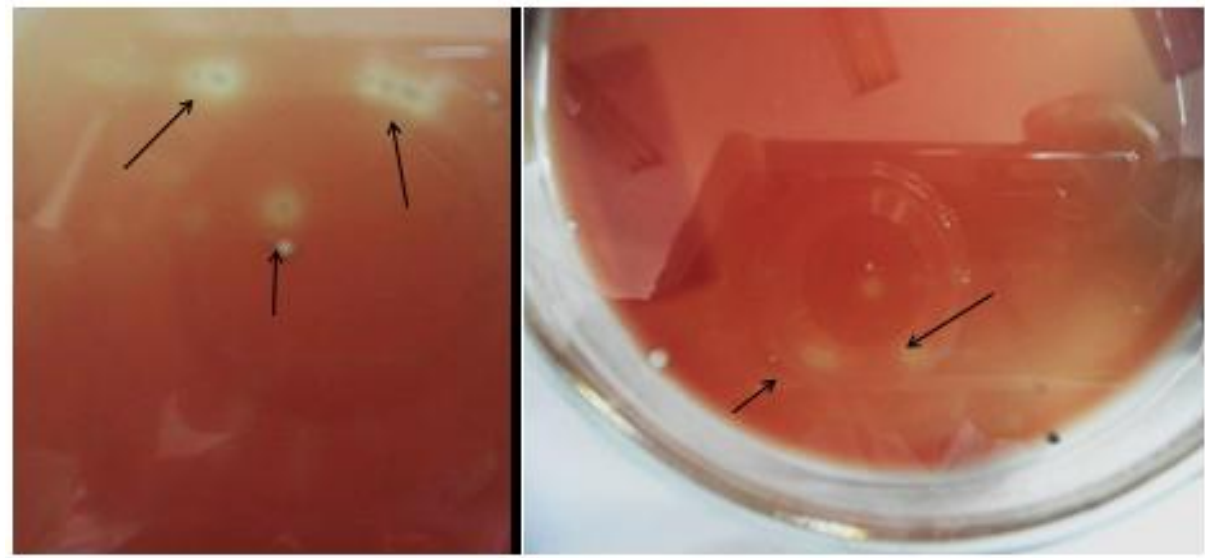

Figure 3. Colonies of Listeria monocytogenes form a zone of hemolysis ( $\beta$ - hemolysis) in blood sheep agar

Listeria monocytogenes creates during exponential phase a toxin called listeriolysin O (hemolysin, which leads to in vitro hemolysin on blood agar (Kasalica et al., 2011) with narrow zone of hemolysis around colonies.

\subsection{Behaviour of Listeria on milk pasteurization}

HTST pasteurization at various temperatures and for 1 minute does not guarantee the death of $L$. monocytogenes. Listeria monocytogenes was the highest level of bacteria at the control temperature, with a result of $7.91 \mathrm{cfu} / \mathrm{ml}$ (Figure 1). Pasteurization temperatures of 75,80 and $85^{\circ} \mathrm{C}$ contained bacterial suspected to be L. monocytogenes, at levels of $5.83,3.82$ and $1.18 \mathrm{cfu} / \mathrm{ml}$, respectively. At 90 and $95^{\circ} \mathrm{C}$, no L. monocytogenes grew. This is in accordance with the SNI, which states that Listeria sp. must be zero (0) to indicate that there is no L. monocytogenes growing on milk. 


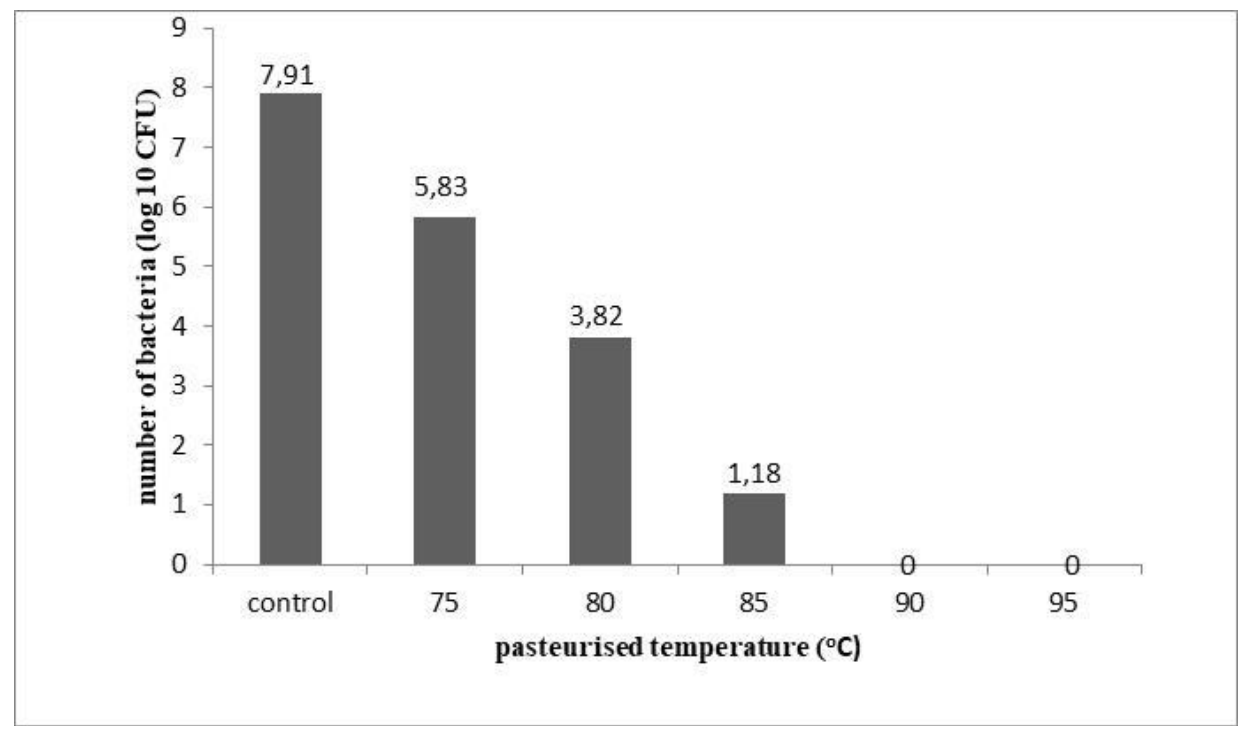

Fig 1. Number of L. monocytogenes bacteria

Pasteurization is expected to kill pathogenic bacteria that exist in fresh milk. Murdiati et al. (2004) stated that the goal of pasteurization is to eliminate pathogenic microbes that are dangerous human health without changing the taste, consistency and nutritional content of milk. According to Hobss and Roberts (1997), the aim of pasteurization is to kill pathogenic bacteria and non-pathogenic bacteria (decay or destruction), as well as to improve milk quality.

Figure 1 shows that the number of $L$. monocytogenes-controlled bacteria in fresh milk was higher because fresh milk is not heated; this means that bacteria can grow in milk because this is a suitable medium for bacterial growth. Heating the milk will cause death and suppress the growth of bacteria. The results of Malaka et al. (2014) showed that the levels of suspected Listeria sp. in fresh milk in South Sulawesi exceeded $3.0 \times 10^{6}$. In fresh milk, microorganisms can be contaminated from the skin of the livestock, feed, air, water and equipment used for rinsing and the storage of feed.

The higher the pasteurization temperature, the lower the number of $L$. monocytogenes (Figure 1). This is consistent with the opinion of Fox and Cameron (1989), that pasteurization at a temperature of $71-75^{\circ} \mathrm{C}$ for 15 seconds only kills $95 \%$ of the bacteria present in the milk so that the quality is greatly influenced by the treatment after heating. One factor that may affect the presence of L.monocytogenes in milk is contamination after pasteurization.

Based on the results of this study (Figure 1), it is known that there are a large number of L. monocytogenes bacteria in raw milk and that milk pasteurized at temperatures of 75,80 and $85^{\circ} \mathrm{C}$ for 1 minute should not be consumed. Milk pasteurized at 90 and $95^{\circ} \mathrm{C}$ for 1 minute in this research is feasible for consumption because, based on previous calculations, the L. monocytogenes estimated bacteria count is 0 . This is in accordance with the Indonesian National Standard (2000) which stated that standard bacterial contamination of Listeria sp. in fresh milk and pasteurized milk should not exist or that 
the amount of Listeria monocytogenes should be zero (0). Navratilova et al. (2004) gave the same result, with positive samples of L. monocytogenes derived from HTST pasteurized milk at a temperature of $72.6^{\circ} \mathrm{C}$ for 15 seconds; the possibility of this microbe existing in milk due to secondary contamination after pasteurization was stated. Nadal et al. (2007) also found that $L$. monocytogenes was able to survive the treatment of milk pasteurized by HTST at a temperature of $72^{\circ} \mathrm{C}$ for 15 seconds. Listeria monocytogenes still survives in HTST pasteurized milk from a temperature of $72-85^{\circ} \mathrm{C}$.

The storage of pasteurized milk at refrigerator temperature indicates the growth of $L$. monocytogenes (Fig. 2). Pasteurization at 90 and $95^{\circ} \mathrm{C}$ showed no L. monocytogenesafter 1 day of storage, but after 1 and 2 weeks of storage there was a suspected level of $L$. monocytogenes. This gives an indication that pasteurization only causes this bacterium to become dormant. The longer the milk is stored, the more Listeria sp. are found, indicating that these bacteria grow in cold storage.

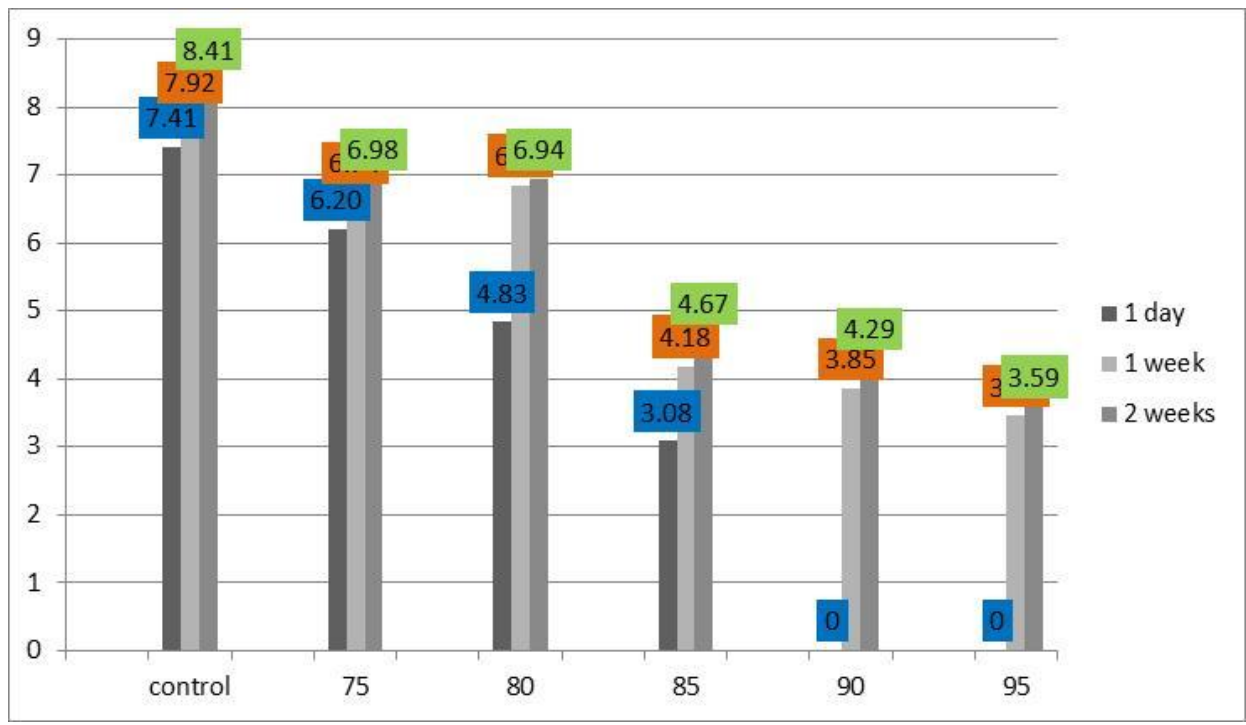

Fig 2. Listeria monocytogenes growth in Refrigerator Storage

Another possibility for the existence of $L$. monocytogenes in pasteurized milk is contamination after pasteurization. This is in accordance with the opinion of Sudarwanto (2012), who stated that pathogenic bacteria will die following a perfect pasteurization process. An outbreak of listeriosis due to the consumption of pasteurized milk is associated with contamination after pasteurization (Schaack and Marth, 1988). AlNabulsi et al. studied the behavior of Listeria monocytogenes during the fermentation and storage of camel milk, and found that the viability of $L$. monocytogenes was not affected during the fermentation of camel milk at $43^{\circ} \mathrm{C}$ for $5 \mathrm{~h}$ for Lactic Acid Bacteria, but it was significantly reduced during storage at 4 or $10^{\circ} \mathrm{C}$.

According to Kusumawati (2000), cooked food, and heated and properly stored food, will be safe to eat because $L$. monocytogenes dies at $75^{\circ} \mathrm{C}$. Chotiah $(2006)$ stated that the main factors that determine the quality of milk following treatment with pasteurization 
are raw materials, processing and packaging.

The pasteurization of milk is generally combined with the cooling method as a preservation technique. The cooling method, at a maximum temperature of $10^{\circ} \mathrm{C}$, extends the shelf-life of pasteurized milk (Setya, 2012). According to Sanjaya et al. (2009) milk should be stored in a refrigerator for no more than 7 days. The presence of the contamination of L. monocytogenes in fresh milk and HTST pasteurized milk during refrigerator storage is due to the nature of $L$. monocytogenes that can grow at low temperatures. This is in accordance with the opinion of Sudarwanto (2012), which states that $L$. monocytogenes is a bacteria that can often cause disease outbreaks due to the consumption of pasteurized milk, because the bacteria are contaminants that can grow at refrigeration temperature. This is supported by Kusumawati (2000), who stated that the potential of $L$. monoytogenes to cause food poisoning is due to its ability to grow in cold storage temperatures $\left(1-10^{\circ} \mathrm{C}\right)$ as a psychophysical bacteria and is even able to survive at frozen storage temperatures. Silva et al. (2003) stated that L. monocytogenes is psychotrophic and can grow at low temperatures.

In addition to the ability to grow at low temperatures, the presence of $L$. monocytogenes during storage may be affected by the presence of Polymorph Nuclear Leucocyte (PMNL) in milk as a factor supporting the cross-contamination after pasteurization and sampling. It can be seen that although L. monoytogenes died after heating at 90 and $95^{\circ} \mathrm{C}$ for 1 minute, it was then detected again after 1 week of storage in the refrigerator (Figure 2). According to Doyle et al. (1987), L. monocytogenes in PMNL is resistant to pasteurization,so the degradation of PMNL and Listeria sp. in milk after being stored in the refrigerator for 3 - 4 days causes the bacteria to regain sensitivity to heating. Therefore, in the case of Listeria contamination, it can be safe for consumption after repeated heating (Tindalization), but this causes the nutritional value of the milk to decrease.

The disease caused by consuming milk contaminated with L. monocytogenes is listeriosis. Symptoms of listeriosis include septicemia, meningitis or meningoencephalitis, encephalitis and uterine or cervical infection in pregnant women, which can result in spontaneous abortion (second/third trimester) or the baby being born and dying soon after. Kusumawati (2000) states that the symptoms of listeriosis begin with influenza and prolonged fever. Listeriosis is characterized by symptoms of the gastrointestinal tract, namely nausea, vomiting, and diarrhea.

One way of handling the effort to preserve milk is by treatment with moderate heating or pasteurization (Sofos, 1993). Prevention efforts that can be performed include avoiding the consumption of raw food, pasteurizing with HTST first in accordance with Good Manufacturing Procedures (GMPs) and applying sanitation hygiene and aseptic technique in every food handling.

Minea et al. (2005) analyzed 196 samples of dairy products in 9 dairy processing plants in 5 countries of the Moldova territory; in total, 20.4\% were identified as being contaminated with Listeria sp., of which $3.57 \%$ were Listeria monocytogenes. The highest frequency of Listeria monocytogenes contamination was registered in raw milk $(10.53 \%)$ and brining maturated cheeses (9.67\%). Minea et al. (2005) concluded that the contamination indicates that Listeria monocytogenes is commonly in the dairy industrial environment. 


\section{Conclusion}

Listeria monocytogenesis is resistant to warming at 75, 80 and $850 \mathrm{o}$ for 1 minute, but increasing the heating temperature causes an increase in bacterial death. Listeria monocytogenes can not survive after warming at 90 and 95oC. Listeria monocytogenes can grow in refrigerator storage temperature $(4 \mathrm{oC})$ and cross-contamination can occur after pasteurization and during processing

\section{Acknowledgement}

The authors would like to thank the Dean of the Faculty of Animal Husbandry, Hasanuddin University for financial support, laboratory facilities and infrastructure. Furthermore, we would like to thank the research institute and community service of Hasanuddin University for funding of Research grant.

\section{References}

Al-Nabulsi, A.A., A.N. Olaimat, T.M. Osaili, M.M. Ayyash, A. Abushelaibi, Z.W. Jaradat, R. Shaker, M. AlTaani, and R.A. Holley (2016) Behavior of Escherichia coli O157:H7 and Listeria monocytogenes during fermentation and storage of camel yoghurt. J. Dairy Sci. 99:1802-1811. https://www. ncbi.nlm.nih.gov/pubmed/26723116

Badan Standar Nasional Indonesia (2000) The maximum limit of microbial contamination and the maximum limit of residuals in foodstuffs of animal origin. SNI No. 01-6366-2000.

Chotiah, S. (2006) List of Microbial Culture Collection Balitvet Culture Collection. Edition 2006. Center for Veterinary Research. Bogor Agricultural Research and Development Agency. P. 24-25.

Doyle, M.P., K.A. Glass, J.T. Berry, G.A. Garsia, D.J. Pollard, and R.D. Schultz. (1987) Survival of Listeria monocytogenes in Milk during High-Temperature, Short-Time Pasteurization. Applied and Environmental Microbiology, 53(7): 1433-1438.

Elrahman, S.M.A.A., A.M.E.M.A, Ahmed, I.E.Y.M.E., Zubair, O.A.O.E, Owni, M.K.A. Ahmed (2013) Effect of storage temperature on the microbiological and physicochemical properties of pasteurized milk. Annals, Food Science and Technology, 14(1): 115-121.

Farber, J.M., and P.I. Peterkin (1991) Listeria monocytogenes, a food-borne pathogen. Microbiology Review, 55: 242-250.

Fox, B.A. dan A. G.Cameron (1989) Food Science, Nutrition and Health. $5^{\text {th }}$ ed. Edward Arnold.London.

Greenwood H., D. Roberts, P. Burden (1991) The occurrence of Listeria spesies in milk and dairy products: a national survey in England and Wales. Int. J. Food Microbiol., 12: 197-206.

Harsoyo and L. Andini (2002) Effect of irradiation and storage of Listeria monocytogenes inoculated in goat meat. National Program of Livestock and Veterinary Technology. Bogor.

Hobbs, B.C. and D. Roberts (1997) Food Poisoning and Food Hygiene. 5th edition. Edward Arnold. London.

Kameni, A., H. Imele, N.J. Mbanya (2002) An alternative heat treatment for milk pasteurizationin Cameroon. International Journal of Dairy Technology, 55(1):40-43.

Kasalica, A., V. Vukovic, A. Vranjes, N. Memisi (2011) Listeria monocytogenes in Milk and Dairy Products. Bioteccnology in Animal Husbandry 27(3): 1067-1082.

Kusumawati, N (2000) The role of lactic acid bacteria in inhibiting Listeria monocytogenes on foodstuffs. Journal of Food and Nutrition Technology, 1 (1): 14 - 28.

Malaka, R., F.N. Yuliati, K.P. Indah, E. Murpiningrum (2014) Isolation and identification of Listeria monocytogenes from fresh milk in South Sulawesi. Research Report, Faculty of Animal Husbandry, Hasanuddin University. Makassar. 
Marth E.H., and T.E. Ryser (1990) Occurrence of Listeria in foods: milk and dairy foods. Food borne Listeriosis. Miller A. J. (ed). Topics in industrial microbiology, Society for industrial Microbiology, Amsterdam.

Menendez, S., Gidinez, M.R., Rodriguez-Otero, J.L., Centeno, J.A. (1997) Removal of Listeria spp in a cheese factory. J. Food Safety, 17: 133-139

McLauchlin, J., R. Mitchell, W. Smerdon, and K. Jewell (2004) Listeria monocytogenes and listeriosis: A review of hazard characterization for use in microbiological risk assessment of foods. Int. J. Food Microbial., 92: 15-33.

Minea, L., O. Drug, C.C.M. Vasilov, D. Bucsae, D. Mircea, C. Gafencu, L.P.Berizintus, M.Cibis, I.S.P.Iasi, D.S.P. Botosani, D.S.P. Galati, D.S.P. Neamt, D.S.P. Bacau, D.S.P. Iasi (2005) The main sources of Listeria monocytogenes contamination in milk processing plants. Journal of Preventive Medicine, 13 (3-4): 43-51.

Nadal, A., A. Coll, N. Cook and M. Pla (2007) A molecular beacon-based realtime NASBA assay for detection of Listeria monocytogenesin food products: Role of target mRNA secondary structure on NASBA design. J. Microbiol. Methods 68: 623 - 632.

Navratilova, P; J. Schlegelova; A. Sustackova; E. Napravnikova; J. Lukasova (2004) Prevalence of Listeria moncytogenes in milk, meat and foodstuff of animal origin and the phenotype of antibiotic resistence of isolated strains. Vet. Med.-Czech, 49: $243-252$.

Paillard, D., V. Dubois, R. Duran, F. Nathier, C. Guittet, P. Caumette, and C. Quentin (2003) Rapid Identification of Listeria Species by using restriction fragment length polymorphism of PCRAmplified 23S rRNA Gene Fragments. Applied and Environmenal Microbiology, 69(1): 63866392.

Rosenow, E.M., Marth, E.H. (1987) Listeria, listeriosis and dairy foods: a review. Cult. Dairy Prod. J. Am. Culture. Dairy Prod. Inst., 13-17.

Sanjaya A, W., Sudarwanto M, and Robert K. (2009) Detection of Listeria Monocytogenes in Pasteurized Milk Sold In Bogor and Its Relationship With Human Health. Faculty of Veterinary Medicine; Institut Pertanian Bogor. Bogor.

Sarkar, S. (2015) Nicrobiological Consideration: Pasteurized Milk. International Journal of Dairy Science 10 (5): 206-218.

Schaack, M.M., Marth, E.H. (1988) Behaviour of Listeria monocytogenes in skim milk during fermentation with mesophilic lactic starter culture. J. Food Prot. $1: 600$.

Setya, A. W. (2012) Technology Milk Processing . Faculty of Agricultural Technology, University SlametRiyadi. Surakarta.

Silva, I.M.M, R.C.C. Almeida, M.A.O. Alves, P.F. Almeida (2003) Occurance of Listeria spp. in critical control points and the environment of Minas Frescal cheese processing. International Journal of food Microbiology, 81: 241-248.

Sofos, J. N. (1993) Current Microbiological Consideration in Food Preservation. Int. J. Food Microbiol. 19: $87-108$.

Sudarwanto, M. (2012) Inspection of Milk and Processed Products. IPB Press. Bogor. 